This paper is a contribution to the special issue on:

Perspectives and tools for conservation risk analysis

\title{
Testing the focal species approach to making conservation decisions for species persistence
}

\section{Authors:}

Emily Nicholson ${ }^{1,2 *}$

David B. Lindenmayer ${ }^{3}$

Karin Frank ${ }^{4}$

Hugh P. Possingham ${ }^{5}$

1. School of Botany, University of Melbourne, Victoria 3010, Australia

2. Division of Biology, Imperial College London, Silwood Park Campus, Buckhurst Road, Ascot, Berkshire, SL5 7PY, United Kingdom

3. Fenner School of Environment and Society, ARC Centre of Excellence for Environmental Decisions and National Environmental Research Program, The Australian National University, Canberra, ACT 0200, Australia

4. Helmholz Centre for Environmental Research - UFZ, Permoserstraße 15, 04318 Leipzig, Germany.

5. School of Biological Sciences, ARC Centre of Excellence for Environmental Decisions and National Environmental Research Program, The University of Queensland, St Lucia, Queensland 4072, Australia

*Corresponding author: Emily Nicholson, emily.nicholson@unimelb.edu.au Words: $\sim 4700$ (excl. reference figures, tables, citations - total 7400, 28 pages 


\begin{abstract}
Aim: Most risk assessments and decisions in conservation are based on surrogate approaches, where a group of species or environmental indicators are selected as proxies for other aspects of biodiversity. In the focal species approach, a suite of species is selected based on life history characteristics, such as dispersal limitation and area requirements. Testing the validity of the focal species concept has proved difficult, due to a lack of theory justifying the underlying framework, explicit objectives and measures of success. We sought to understand the conditions under which the focal species concept has merit for conservation decisions.

Location: Our model system comprised ten vertebrate species in 39 patches of native forest embedded in pine plantation in New South Wales, Australia.

Methods: We selected three focal species based on ecological traits. We used a multiplespecies reserve selection method that minimizes the expected loss of species, by estimating the risk of extinction with a metapopulation model. We found optimal reserve solutions for multiple species, including all ten species, the three focal species, for all possible combinations of three species, and for each species individually.

Results: Our case study suggests that the focal species approach can work: the reserve system that minimized the expected loss of the focal species also minimized the expected species loss in the larger set of ten species. How well the solution would perform for other species and landscape dynamics remains unknown.

Main conclusions: The focal species approach may have merit as a conservation short-cut if placed within a quantitative decision-making framework, where the aspects of biodiversity for which the focal species act as proxies are explicitly defined, and success is determined by whether the use of the proxy results in the same decision. Our methods provide a framework for testing other surrogate approaches used in conservation decision-making and risk assessment.
\end{abstract}

Key words: conservation planning; extinction risk; focal species; indicator species; metapopulation; population viability analysis 


\section{Introduction}

Risk assessment in conservation and subsequent management decisions often use indicator or surrogate species to assess the impacts of management actions on biodiversity. Such proxies for the rest of biodiversity are needed due to a lack of information on the distribution of other species and their responses to management, the complexity of many ecosystem responses to management, and because resources to evaluate impacts on biodiversity are limited (Lindenmayer \& Likens, 2011). Criteria are therefore needed for selecting a subset of species that encapsulate the responses of other species in the system (Roberge \& Angelstam, 2004; Favreau et al., 2006; Lindenmayer \& Likens, 2011). Lambeck (1997) proposed the focal species approach in an attempt to accommodate processes that threaten species viability, such as fragmentation, loss of habitat, and feral predators, into conservation assessments. In Lambeck's (1997) approach, a suite of focal species is selected on the basis of life-history characteristics to develop conservation plans that are expected to confer protection to other co-occurring species facing similar threats (Fleishman et al., 2000; Beazley \& Cardinal, 2004; Roberge \& Angelstam, 2004).

The two primary criticisms of the focal species approach are the lack of a well-defined framework for decision-making, and a lack of evidence to support the underlying principle that focal species confer protection to co-occurring species facing similar threats (Lindenmayer et al., 2002; Roberge \& Angelstam, 2004; Branton \& Richardson, 2011; Sætersdal \& Gjerde, 2011). These two problems are interrelated: it is difficult to evaluate a theory without explicit goals and performance measures (Westphal \& Possingham, 2003; Nicholson \& Possingham, 2006). Because the focal species concept is based on population processes and the persistence of species, both the goal and the responses of the focal and non-focal species should be measured in terms of extinction risk, which gives a common currency across the species (Lindenmayer et al., 2002; Nicholson \& Possingham, 2006).

Previous studies are equivocal about the merits of the focal-species approach in conservation planning (Branton \& Richardson, 2011). Most negative assessments of the 
focal-species approach assess mismatches in species distribution rather than persistence (e.g. Andelman \& Fagan, 2000; Fleishman et al., 2001; Manne \& Williams, 2003; Cabeza et al., 2008). Few studies evaluate the effectiveness of focal species for delivering viable populations of all the species in the system (Favreau et al., 2006). Caro (2003) and Berger (1997) assess the capacity of current national parks set aside (although not designed systematically) for large wide-ranging mammals to support other vertebrate species, but their results were inconclusive given the effects of poaching and other threats. Alexander et al. (2007) report that increases in abundance in focal species reflected similar trends in non-focal species, but not reliably. McCarthy et al. (2006) give qualified support to the focal species concept, finding that the most extinction-prone species are critical in driving conservation decisions based on population models. They do not consider how we might identify the focal species a priori, based on population processes; nor do they test the capacity of a set of focal species to ensure the viability of other species (McCarthy et al., 2006).

Many criteria have been proposed for identifying focal species based on ecological processes (see reviews in Beazley \& Cardinal, 2004; Roberge \& Angelstam, 2004; Seddon \& Leech, 2008; Branton \& Richardson, 2011), most of which can be associated with demographic parameters within a population biology framework (Henle et al., 2004), including:

1) area-limited species (Lambeck, 1997; Beazley \& Cardinal, 2004), with large area requirements and low population densities; this equates to high local extinction rates in metapopulation theory and low carrying capacity (Henle et al., 2004);

2) dispersal-limited species (Lambeck, 1997; Beazley \& Cardinal, 2004), with poor dispersal abilities, which equates to low colonization rates in metapopulation theory (Henle et al., 2004); and

3) species with low reproductive potential or fecundity (Beazley \& Cardinal, 2004; Seddon \& Leech, 2008), which results in both a low population growth rate and a reduced rate of emigration and colonization in a metapopulation (Henle et al., 2004). 
In this study we explored the implications of using the focal species approach as a shortcut when planning for the persistence of multiple species. We sought to understand the conditions under which the focal species concept has merit for conservation planning. If the overall goal is to conserve as many species as possible within a reserve system, what are the consequences of using a subset of species to make the conservation planning decision? We used a method for conservation planning that maximizes the persistence of multiple species (Nicholson et al., 2006), where the extinction risk is estimated using a metapopulation model (Frank \& Wissel, 2002), a function of the amount, quality and configuration of habitat patches and the ecology of the species. We related the criteria for selecting the focal species to key model parameters for dispersal capability, home range size and fecundity. Using these criteria, we identified a subset of three focal species from a set of ten vertebrate species that inhabit a 39 patch system in New South Wales, Australia. We asked if the reserve solution that minimized the expected extinctions in the subset of focal species was the same as the solution that minimized the expected number of extinctions across all ten species.

\section{Methods}

\section{Case study}

We focused on a case study comprising ten species of vertebrates inhabiting 39 patches of eucalypt (Eucalyptus spp.) forest embedded in approximately 100,000 ha of Monterey pine (Pinus radiata) plantations (Figure 1). This highly fragmented system, near Tumut in New South Wales, Australia, has been extensively studied over many years, including field-based and modelling research (Lindenmayer et al., 2003; Lindenmayer, 2009). The primary threat to biodiversity in this system is the effects of fragmentation and habitat loss. The ten species modelled were selected because they were expected to respond to the landscape scale of disturbance, and had been the subject of extensive research, including several modelling studies (Lindenmayer et al., 2003). The ten species represent a range of body sizes and life history strategies, and include four bird species, five marsupials and one native rodent. Table 1 lists the parameter values used in the 
metapopulation models for each of the species, habitat suitability in the different habitat types, and the published population models used to derive the parameter values. For simplicity, we assumed that the species do not use the pine plantation matrix as primary habitat, but are able to disperse through it, and that dispersal between patches is a function of distance. Note that the case study provides a model system for testing the focal species concept, rather than providing a management plan for the forest; indeed, large fires in the landscape and forestry activities have altered the system extensively in the last 5 years (Youngentob et al., 2012).

\section{Conservation planning method}

The objective of our reserve selection problem was to minimize the expected number of extinctions given by the sum of the extinction risks of the species under consideration, subject to an area budget (in this case $220 \mathrm{ha}$ ),:

$$
\text { minimise } \sum_{k=1}^{n} p_{k}(\mathbf{r}) \text {, s.t. } \mathrm{A}_{\mathbf{r}} \leq 220 \text { ha }
$$

where $p_{k}(\mathbf{r})$ is the extinction risk of species $k$ in reserve system $\mathbf{r}, n$ is the number of species under consideration, and $A_{\mathbf{r}}$ is the total area of reserve system $\mathbf{r}$. We estimated the probability of extinction of the metapopulation of species $k$ over 100 years in the reserve system $\mathbf{r}, p_{k}(\mathbf{r})$, using the approximation formula for the mean time extinction developed by Frank and Wissel (2002) from a time-continuous, spatially explicit metapopulation model (Frank \& Wissel, 1998). The mean time to extinction of species $k$ given the reserve system $\mathbf{r}$ is given by the effective colonization abilities of the subpopulations $z$, the effective local extinction rate $v_{a g g}$, and the number of patches $M$, as shown in Table 2 . Extinction risk of species $k$ is a function of the area, quality and spatial configuration of the patches of habitat in the reserve system $\mathbf{r}$, and four species-specific parameters (Nicholson et al., 2006):

1. the home range size, $H_{k}$;

2. the mean dispersal distance, $d_{k}$; 
3. the emigration rate per home range, given by the estimated average number of female juveniles produced annually by a breeding female, $\gamma_{k}$; and

4. the extinction-area exponent, $x_{k}$, a species-specific measure of environmental noise in the population that includes both the strength of the fluctuations in environmental factors and the sensitivity of the species to them (Hanski, 1998; Frank, 2004); low values of $x_{k}$ indicate that a species can experience large fluctuations in abundance through time, and consequently even large patches have a substantial risk of local extinction (Hanski, 1998; Frank, 2004).

We did not include spatial correlation in environmental stochasticity for simplicity's sake, though this would undoubtedly have an impact on the resultant reserve systems and estimates of extinction risk. Whether it would affect the efficacy of the focal species approach could be tested in a sensitivity analysis, in addition to assessing the sensitivity of the results to other parametric and model uncertainty (Nicholson \& Possingham, 2007).

The sub-model for the local extinction rate of a population of species $k$ in patch $i, v_{i}$ (Table 2), is a function of the extinction-area exponent $x_{k}$, and the effective number of home ranges contained in the patch. We assume that the habitat quality affects population density (e.g., Johnson et al., 2005), and therefore habitat of lower quality (where the measure of habitat quality $h_{i k}$ is less than 1) can support fewer home ranges for breeding females. As $H_{k}$ is the home range size of species $k$ in optimal habitat, and $h_{i k}$ is the proportional decrease in density of species $k$ in patch $i$ given sub-optimal habitat, the effective home ranges of species $k$ in patch $i$ is given by $\frac{A_{i} h_{i k}}{H_{k}}$. Finally, we assume that the local extinction risk of a patch is $99 \%$ when it is the size of one effective home range, giving a coefficient to the local extinction rate of $\frac{-\ln (0.01)}{100}$. The function for the local extinction rate is therefore given by: 


$$
v_{i}=\frac{-\ln (0.01)}{100}\left(\frac{A_{i} h_{i k}}{H_{k}}\right)^{-x_{k}}
$$

The rate of colonization from patch $i$ to $\operatorname{patch} j, c_{i j}$ (Table 2), was estimated with the pieslice model (Possingham et al., 1994; Nicholson et al., 2006):

$$
c_{i j}=\gamma_{k} \frac{A_{i} h_{i k}}{H_{k}} b e^{-d_{i j} / d_{k}}
$$

where the likelihood of colonization is a function of: the mean dispersal distance of species $k, d_{k}$; the output rate of potential colonizers from patch $i$, a function of the emigration rate per home range, $\gamma_{k}$, and the effective number of home ranges in patch $i$, $\frac{A_{i} h_{i k}}{H_{k}}$; and the size and distance of the recipient patch $j$, the 'pie slice' component of the model, given by $b$, where $b=\frac{1}{\pi} \arctan \left(\frac{\sqrt{A_{j} / \pi}}{d_{i j}}\right)$ for $d_{i j} \geq \sqrt{A_{j} / \pi}$ and $b=0.5$ when $d_{i j}<\sqrt{A_{j} / \pi}$

We found the optimal or near-optimal reserve solution that minimized the expected number of extinctions using simulated annealing, a heuristic optimization algorithm (Kirkpatrick et al., 1983; Nicholson et al., 2006). Simulated annealing is a stochastic search algorithm, with potential reserves randomly included and excluded from the reserve system. At each change the objective function and its constraints (in this case, minimizing the expected number of extinctions while ensuring the reserve system is no larger than 220ha) are assessed. In the early stages of the algorithm, 'bad' changes are allowed to explore the potential options and reduce the chance of becoming stuck in a local minimum. As the algorithm progresses, only changes that improve the objective function are permitted, converging on an optimal or near-optimal solution. Because simulated annealing is stochastic, there is no guarantee of finding the optimal solution. 
Therefore, we ran each scenario 100 times to maximize the likelihood of finding the optimal solution.

\section{Selecting the focal species}

To identify the focal species, we used criteria outlined by Lambeck (1997) and Beazley and Cardinal (2004) of large area requirements, dispersal limitation and low fecundity. Each of these criteria has a direct relationship to key parameters in our metapopulation model, giving three focal species: the species with the largest home range size, $H_{k}$, the shortest mean dispersal distance, $d_{k}$, and the lowest species-specific emigration rate per home range, $\gamma_{k}$, estimated as the number of juveniles produced per breeding female. The three parameters used as focal species criteria therefore represent key model parameters that can be estimated, or which can be used to rank a broader set of species of interest to identify the sub-set of focal species.

We elected not to use the extinction-area exponent, $x_{k}$, as a focal species criterion. Unlike the other parameters, the extinction-area exponent $x_{k}$ does not relate to a readily measurable biological trait, and, due to its complexity and composite nature, would require a long time series or a detailed population model to estimate. Restricted habitat or habitat specificity could have formed further selection criteria for a focal species, which could relate in our models to $h_{i k}$, the reduced density in sub-optimal habitat. However, all but two of the our study species can be found in all habitat types in the study patches (with the exception of the bush rat and the mountain brushtail possum, for which the majority of patches were still suitable), rendering it a relatively uninformative criterion in this case (although note that these two species were selected as focal species based on other focal species criteria). Sensitivity analyses found the effectiveness of the focal species approach was insensitive to the inclusion of habitat suitability in the metapopulation model (Nicholson, 2006).

To test the focal species approach, we varied the number of species modelled. In all cases the total area of the reserve system was not permitted to exceed 220 ha, half of the total 
area of the patches. First, we solved the single-species planning problem, and found the reserve solutions that minimized the extinction risk for each of the ten species separately. We then found the reserve system that minimized the expected number of extinctions across all ten species. We considered this the best reserve system that we could derive, based on all available information, and used it as our reference point for the reserve systems identified using subsets of species. To test whether the subset of focal species could provide a short-cut for conservation planning, we found the reserve solution that minimized the expected extinctions across the three focal species. We also found the best reserve systems for all 120 possible sets of three species, and compared them with the ten-species reserve solution to test if any other three-species combination would deliver the same result.

\section{Results}

The most area-limited species was the red-browed treecreeper, with a home range of 10 ha (Table 3). The mountain brushtail possum was the species with the lowest fecundity, here measured as the lowest output of emigrants per unit area, giving low colonization rates. The bush rat was the most dispersal-limited, with a mean dispersal distance of 100 m.

For each species there were one or more optimal reserve solutions that minimized extinction risk (Table 4; Figure 2, for the focal species only). The reserve systems that minimized the extinction risk for each species differed because of the species' ecological traits, supporting the need to model more than one species. For example, the best reserve solution for the red-browed treecreeper included the largest areas (Figure 2b).

We found that the reserve solution that minimized the expected number of extinctions across the three focal species was the same as the reserve solution that minimized the expected extinctions across all ten species (Figure 2, Table 4). The three focal species determined the best ten-species reserve solution; the seven non-focal species did not influence the conservation decision because their lower extinction risks had negligible impact on the objective value in comparison with the more extinction-prone focal species 
(Table 4). Of the 120 possible combinations of three species, only the focal species combination delivered the same reserve system as the ten-species solution. The best multiple-species reserve solution differed from the single-species solutions (Figure 2). The extinction risk of each focal species was higher in the multiple-species reserve solutions than in the optimal single-species reserve solutions (Table 4). The multi-species solution was therefore a compromise reserve system that balanced the needs of more than one species.

Of the remaining 119 three-species combinations, none were the same as the ten-species solution. However, 68 three-species solutions were the same as one of the single-species solutions. This was the case when a species with a relatively high extinction risk was combined with two species with much lower extinction risks, and thus the extinctionprone species dominated the solution. This pattern is illustrated by the rank order of the species by extinction risk and the number of three-species solutions that matched their optimal single-species solution (Table 4). Interestingly, there were six examples where the optimal three-species solution was the same as the optimal single-species solution for the common brushtail possum, in five of which the possum was not included amongst the three species - it would appear that by chance the best habitat configuration for the common brushtail was also a good compromise landscape for other species.

The three-species solutions that included two focal species in almost all cases had the same result per focal pair, i.e. all combinations of the red-browed treecreeper and mountain brushtail possum were the same, with a separate optimal solution for all but one combination of the red-browed treecreeper and bush rat, and a different optimum again for all but two combinations of the bush rat and mountain brushtail possum. In other words, when two focal species were included, the third species (if not a focal species) had no bearing on the resultant landscape. Exceptions to this rule were provided by two examples when a third extinction-prone species, the greater-glider, was included with two of the focal species (the bush rat and either of the other two focal species). In both cases, in the optimal three-species solution the glider had a higher extinction risk than the bush rat, and thus drove the result. The final exception was when the bush rat and mountain 
brushtail were combined with the antechinus, when a very small patch that was unsuitable for either focal species but suitable for the antechinus was included.

\section{Discussion}

We obtained evidence that the focal species approach worked for our case study: the reserve system that minimized the expected loss of the focal species also minimized the expected loss in the larger set of ten species. The subset of extinction-prone species that drove the conservation planning decision could be identified a priori using the focal species approach, specifically the most dispersal-limited, area-limited and least fecund species. Thus, although the focal species approach has some theoretical shortcomings (Lindenmayer et al., 2002; Favreau et al., 2006; Lindenmayer \& Likens, 2011), our study shows that it may help managers make good conservation decisions, while saving time and data requirements. However, it is critical that the aspects of biodiversity for which the focal species are acting as surrogates are defined and bounded (Lindenmayer \& Likens, 2011). The three focal species in our study worked well as surrogates for the set of ten target species, but it remains unknown how they perform for other species, processes and ecological communities, and also how they might perform over time, such as the when landscape surrounding the remnant eucalypt patches is transformed (e.g. clearfelling of the plantation, see Lindenmayer et al., 2008).

Our assessment of the focal species approach leads us back to the purpose of the concept, and how to measure its success in conferring protection to other species. What aspect of the focal species approach have we tested here? We did not seek the optimal solution for all seven non-focal species, or try to meet the needs of a 'super-species', with poor dispersal and large area requirements. Nor did we aim for a viability threshold for each species, such as a 5\% risk of extinction over 100 years (Vos et al., 2001) or a treatment of the economic and conservation trade-offs of the alternative options (e.g. Hester et al. 2013). Indeed the general recommendations of the PVA literature are to use models as relative predictors of management options, rather than to rely on uncertain, absolute estimates of extinction risk (Ball et al., 2003; McCarthy et al., 2003). 
Our measure of the performance is the expected loss of species from the reserve network, which is the sum of the extinction risk estimates over the modelled species. This provides a solution that is a trade-off between differing needs of the modelled species. Our measure of the success of the focal species approach is whether the same decision would be made with the full set of species or the sub-set of focal species. In general, a species with a low extinction risk will have little influence on the expected loss of species compared with a more extinction-prone species. Consequently, we find that most of the species in this case study have no influence on the best reserve system, while the most extinction-prone species tend to dominate the three-species solutions. Alternative goals for multiple-species conservation planning, for example minimizing the risk of losing any species rather than the expected loss of species (e.g. Nicholson \& Possingham, 2006), may offer different evaluations of the focal species approach, and could be assessed as part of a sensitivity analysis. Methods for finding solutions other than through optimization of a utility function (in this case expected species loss), such as multicriteria decision analysis (Drechsler, 2004; Nicholson \& Possingham, 2007), may also yield different success rates for the focal species approach.

\section{Caveats}

The apparent success of the focal species approach in our case study may be due to the relatively small set of target species, with most species able to use all habitat types. In a larger scale case study, with more diverse habitat types and more distinct distributions of species, the less extinction-prone species may have a greater impact on the objective. The focal species approach may prove less successful when species distribution and habitat requirements as well as ecological characteristics are more incompatible. Key questions remain: how many species, or what proportion of the total number of species, are necessary to select to achieve good coverage of the other species of interest? Given that our assessment of the focal species criteria was relative to some larger set of target species (in this case ten), how inclusive should the larger set of species be? Further case studies are required to allow a more thorough exploration of the role of focal species in risk assessment and conservation decision-making, and to provide rules-of-thumb about 
when the focal species approach works, how many and which criteria are appropriate for given the threats facing biodiversity in a given landscape, and the definition of the aspects of biodiversity the focal species represent.

Although the focal species were selected on the basis of a single life-history characteristic, one key trait may not suffice to predict extinction proneness and sensitivity to the configuration of reserves (Henle et al., 2004). A focal species selected under one criterion may also be vulnerable for other reasons. In our case study, the focal species were also somewhat vulnerable with regard to other life history attributes (Table 3); for example, the red-browed treecreeper was relatively dispersal-limited, the bush rat and mountain brushtail possum had the most restricted habitat distributions, and the bush rat had the lowest extinction-area exponent, $x$, and thus highest local extinction rates per home range. Furthermore, home range size is important in both the extinction and colonization functions.

Model parameters can interact to influence the predicted extinction risk of the species in two ways (Milner-Gulland et al., 2001; Henle et al., 2004): low values in multiple attributes, such as dispersal ability and fecundity, may compound to increase extinction risk non-linearly, while strengths in one life-history attribute and model parameter can compensate for limitations in another; for example, good dispersal may compensate for big fluctuations in abundance leading to high local extinction rates. Furthermore, ecological traits are not independent: species with large home range sizes tend to have long dispersal distances and low fecundity, typically relating to body size (Bowman et al., 2002; Biedermann, 2003; Manne \& Williams, 2003; Whitmee \& Orme, 2012). Similarly, the extinction-area exponent, $x_{k}$, has been found to be positively correlated with body size (Cook \& Hanski, 1995).

In the metapopulation paradigm, the best reserve systems tend to include large and connected patches. This tendency was accentuated in our study landscape because the central patches were large, and we did not consider correlations in local extinction. We applied the same metapopulation model to all species in the system, when other 
modelling frameworks may be more appropriate for some species (Lindenmayer et al., 2003). For example, the bush rat has very limited dispersal (Peakall et al., 2006), and previous modelling studies have found that models with restricted or no dispersal provided the best fit to data from the same region (Lindenmayer \& Lacy, 2002; Ball et al., 2003). The model we used approximates the mean time to extinction based on a stochastic model (Frank \& Wissel, 2002), and assumes a static landscape (although see developments in Drechsler \& Johst, 2010). Thus the risk of extreme events and their impacts, such as fire or drought, and dynamics of landscape change (such as forestry activities and fire) are not well accounted for. Simulation models may provide a better estimate of the impacts of stochastic events and landscape dynamics (Keith et al., 2008).

Uncertainty in key focal parameters could result in a different set of focal species being selected. For example, if home range size for one of the species was under-estimated, it might not be identified as the focal species for area-limitation. This could be addressed by an extensive sensitivity analysis across all or key parameters (e.g., Nicholson \& Possingham, 2007; Naujokaitis-Lewis et al., 2009). Such a sensitivity analysis could reduce the risk of selecting the wrong set of focal species due to limited information.

Our analysis of the focal species approach was for a single point in time. Useful future analyses could include repeated simulations to quantify changes in landscape cover surrounding the 39 patches of remnant eucalypt forest (see Lindenmayer, 2009; Youngentob et al., 2012) and its influence on the outcomes of the focal species approach. This would also allow the models to be updated and revised as understanding of the management of the landscape matrix improves (Keith et al., 2011). Thus although in our case study the best landscape for the focal species was the same as that for the larger set of species, because of the many sources of uncertainty in the models described above, it could still lead to poor decisions.

\section{Conclusions}

We were able to assess the merits of the focal species approach for making decisions based on proxies because we used decision analysis to define the problem. We had an 
explicit objective, to minimize the net loss of species, with a quantitative relationship between management options and extinction risk. We defined and bounded the broader group of species for which our focal species were to act as proxies, and used ecological theory to select our focal species, based on population processes. Finally, we had a clear measure of success or failure of the proxy: would our decision change if we used the focal species rather than the larger set of species they were selected from? The focalspecies approach is used in aspects of conservation other than the design of conservation areas, for example, in restoration (e.g. Watson et al., 2001), threat abatement (e.g. Lambeck, 1997), and as indicator species for monitoring (e.g. Alexander et al., 2007; Regan et al., 2008). Our results may not hold for these other uses. Nevertheless, any application of the focal-species approach, and indeed any other surrogate or indicator approach, would benefit from integration into a decision analytic framework to ensure that the goals are explicitly defined, and that success or failure can be assessed. We strongly encourage further evaluation of the focal-species approach, to assess its merit across the full spectrum of conservation decision-making and risk assessment.

\section{Acknowledgements}

The authors thank Bob Pressey, Wayne Rochester, Helen Regan and Jana Verboom for comments on earlier drafts, Mick McCarthy for discussion, and Matt Watts for assistance with GIS. EN was supported by an Australian Postgraduate Award, Forestry Tasmania, a Marie Curie Fellowship (IIF: 221050), and a Centenary Research Fellowship. HPP was supported by an ARC Fellowship.

\section{References}

Alexander, J.D., Seavy, N.E. \& Hosten, P.E. (2007) Using conservation plans and bird monitoring to evaluate ecological effects of management: An example with fuels reduction activities in southwest Oregon. Forest Ecology and Management, 238, 375-383. 
Andelman, S.J. \& Fagan, W.F. (2000) Umbrellas and flagships: Efficient conservation surrogates or expensive mistakes? Proceedings of the National Academy of Sciences USA, 97, 5954-5959.

Ball, S.J., Lindenmayer, D.B. \& Possingham, H.P. (2003) The predictive accuracy of population viability analysis: a test using data from two small mammal species in a fragmented landscape. Biodiversity and Conservation, 12, 2393-2413.

Beazley, K.F. \& Cardinal, N. (2004) A systematic approach for selecting focal species for conservation in the forests of Nova Scotia and Maine. Environmental Conservation, 31, 91-101.

Berger, J. (1997) Population constraints associated with the use of black rhinos as an umbrella species for desert herbivores. Conservation Biology, 11, 69-78.

Biedermann, R. (2003) Body size and area-incidence relationships: is there a general pattern? Global Ecology and Biogeography, 12, 381-387.

Bowman, J., Jaeger, J.A.G. \& Fahrig, L. (2002) Dispersal distance of mammals is proportional to home range size. Ecology, 83, 2049-2055.

Branton, M. \& Richardson, J.S. (2011) Assessing the Value of the umbrella-species concept for conservation planning with meta-analysis. Conservation Biology, 25, $9-20$.

Cabeza, M., Arponen, A. \& Van Teeffelen, A. (2008) Top predators: hot or not? A call for systematic assessment of biodiversity surrogates. Journal of Applied Ecology, 45, 976-980.

Caro, T.M. (2003) Umbrella species: critique and lessons from East Africa. Animal Conservation, 6, 171-181.

Cook, R.R. \& Hanski, I. (1995) On expected lifetimes of small-bodied and large-bodied species of birds on islands. American Naturalist, 145, 307-315.

Drechsler, M. (2004) Model-based conservation decision aiding in the presence of goal conflicts and uncertainty. Biodiversity and Conservation, 13, 141-164.

Drechsler, M. \& Johst, K. (2010) Rapid viability analysis for metapopulations in dynamic habitat networks. Proceedings of the Royal Society B, 277, 1889-1897. 
Favreau, J.M., Drew, C.A., Hess, G.R., Rubino, M.J., Koch, F.H. \& Eschelbach, K.A. (2006) Recommendations for assessing the effectiveness of surrogate species approaches. Biodiversity and Conservation, 15, 3949-3969.

Fleishman, E., Murphy, D.D. \& Brussard, P.E. (2000) A new method for selection of umbrella species for conservation planning. Ecological Applications, 10, 569-579.

Fleishman, E., Blair, R.B. \& Murphy, D.D. (2001) Empirical validation of a method for umbrella species selection. Ecological Applications, 11, 1489-1501.

Frank, K. (2004) Ecologically differentiated rules of thumb for habitat network design lessons from a formula. Biodiversity and Conservation, 13, 189-206.

Frank, K. \& Wissel, C. (1998) Spatial aspects of metapopulation survival - from model results to rules of thumb for landscape management. Landscape Ecology, 13, 363379.

Frank, K. \& Wissel, C. (2002) A formula for the mean lifetime of metapopulations in heterogeneous landscapes. American Naturalist, 159, 530-552.

Hanski, I. (1998) Connecting the parameters of local extinction and metapopulation dynamics. Oikos, 83, 390-396.

Henle, K., Davies, K.F., Kleyer, M., Margules, C. \& Settele, J. (2004) Predictors of species sensitivity to fragmentation. Biodiversity and Conservation, 13, 207-251.

Hester, S. M., Cacho, O. J., Panetta, F. D., and Hauser, C. E. (2013). Economic aspects of post-border weed risk management. Diversity and Distributions, 19, (in press).

Johnson, C.N., Vernes, K. \& Payne, A. (2005) Demography in relation to population density in two herbivorous marsupials: testing for source-sink dynamics versus independent regulation of population size. Oecologia, 143, 70-76.

Keith, D.A., Martin, T.G., McDonald-Madden, E. \& Walters, C. (2011) Uncertainty and adaptive management for biodiversity conservation. Biological Conservation, 144, 1175-1178.

Keith, D.A., Akçakaya, H.R., Thuiller, W., Midgley, G.F., Pearson, R.G., Phillips, S.J., Regan, H.M., Araújo, M.B. \& Rebelo, T.G. (2008) Predicting extinction risks under climate change: coupling stochastic population models with dynamic bioclimatic habitat models. Biology Letters, 4, 560-563 
Kirkpatrick, S., Gelatt, C.D. \& Vecchi, M.P. (1983) Optimization by simulated annealing. Science, 220, 671-680.

Lambeck, R.J. (1997) Focal species: a multi-species umbrella for nature conservation. Conservation Biology, 11, 849-856.

Lindenmayer, D. \& Likens, G. (2011) Direct measurement versus surrogate indicator species for evaluating environmental change and biodiversity loss. Ecosystems, 14, 47-59.

Lindenmayer, D.B. (2009) Large-scale landscape experiments: Lessons from Tumut. Cambridge University Press, Cambridge.

Lindenmayer, D.B. \& Lacy, R.C. (2002) Small mammals, habitat patches and PVA models: a field test of model predictive ability. Biological Conservation, 103, 247-265.

Lindenmayer, D.B., McCarthy, M.A. \& Pope, M.L. (1999) Arboreal marsupial incidence in eucalypt patches in south-eastern Australia: a test of Hanski's incidence function metapopulation model for patch occupancy. Oikos, 84, 99-109.

Lindenmayer, D.B., Lacy, R.C. \& Pope, M.L. (2000) Testing a simulation model for population viability analysis. Ecological Applications, 10, 580-597.

Lindenmayer, D.B., McCarthy, M.A., Possingham, H.P. \& Legg, S. (2001) A simple landscape-scale test of a spatially explicit population model: patch occupancy in fragmented south-eastern Australian forests. Oikos, 92, 445-458.

Lindenmayer, D.B., Possingham, H.P., Lacy, R.C., McCarthy, M.A. \& Pope, M.L. (2003) How accurate are population models? Lessons from landscape-scale tests in a fragmented system. Ecology Letters, 6, 41-47.

Lindenmayer, D.B., Manning, A.D., Smith, P.L., Possingham, H.P., Fischer, J., Oliver, I. \& McCarthy, M.A. (2002) The focal-species approach and landscape restoration: a critique. Conservation Biology, 16, 338-345.

Lindenmayer, D.B., Cunningham, R.B., MacGregor, C., Crane, M., Michael, D., Fischer, J., Montague-Drake, R., Felton, A. \& Manning, A. (2008) Temporal changes in vertebrates during landscape transformation: a large-scale "natural experiment". Ecological Monographs, 78, 567-590. 
Manne, L.L. \& Williams, P.H. (2003) Building indicator groups based on species characteristics can improve conservation planning. Animal Conservation, 6, 291297.

McCarthy, M.A., Lindenmayer, D.B. \& Possingham, H.P. (2000) Testing spatial PVA models of Australian treecreepers (Aves: Climacteridae) in fragmented forest. Ecological Applications, 10, 1722-1731.

McCarthy, M.A., Lindenmayer, D.B. \& Possingham, H.P. (2001) Assessing spatial PVA models of arboreal marsupials using significance tests and Bayesian statistics. Biological Conservation, 98, 191-200.

McCarthy, M.A., Andelman, S.J. \& Possingham, H.P. (2003) Reliability of relative predictions in population viability analysis. Conservation Biology, 17, 982-989.

McCarthy, M.A., Thompson, C.J. \& Williams, N.S.G. (2006) Logic for designing nature reserves for multiple species. American Naturalist, 167, 717-727.

Milner-Gulland, E.J., Shea, K., Possingham, H., Coulson, T. \& Wilcox, C. (2001) Competing harvesting strategies in a simulated population under uncertainty. Animal Conservation, 4, 157-167.

Naujokaitis-Lewis, I.R., Curtis, J.M.R., Arcese, P. \& Rosenfeld, J. (2009) Sensitivity Analyses of Spatial Population Viability Analysis Models for Species at Risk and Habitat Conservation Planning. Conservation Biology, 23, 225-229.

Nicholson, E. (2006) Planning for persistence: using the risk of extinction in multispecies approaches to conservation planning. PhD Thesis. The University of Queensland, Brisbane, Australia.

Nicholson, E. \& Possingham, H.P. (2006) Objectives for multiple-species conservation planning. Conservation Biology, 20, 871-881.

Nicholson, E. \& Possingham, H.P. (2007) Making conservation decisions under uncertainty for the persistence of multiple species. Ecological Applications, 17, 251-265.

Nicholson, E., Westphal, M.I., Frank, K., Rochester, W.A., Pressey, R.L., Lindenmayer, D.B. \& Possingham, H.P. (2006) A new method for conservation planning for the persistence of multiple species. Ecology Letters, 9, 1049-1060. 
Peakall, R., Ebert, D., Cunningham, R. \& Lindenmayer, D.B. (2006) Mark-recapture by genetic tagging reveals restricted movements by bush rats (Rattus fuscipes) in a fragmented landscape. Journal of Zoology, 268 207-216.

Possingham, H.P., Lindenmayer, D.B., Norton, T.W. \& Davies, I. (1994) Metapopulation viability analysis of the greater glider Petauroides volans in a wood production area. Biological Conservation, 70, 227-236.

Regan, H.M., Hierl, L.A., Franklin, J., Deutschman, D.H., Schmalbach, H.L., Winchell, C.S. \& Johnson, B.S. (2008) Species prioritization for monitoring and management in regional multiple species conservation plans. Diversity and Distributions, 14, 462-471.

Roberge, J.-M. \& Angelstam, P. (2004) Usefulness of the umbrella species concept as a conservation tool. Conservation Biology, 18, 76-85.

Sætersdal, M. \& Gjerde, I. (2011) Prioritising conservation areas using species surrogate measures: consistent with ecological theory? Journal of Applied Ecology, 48, 1236-1240.

Seddon, P.J. \& Leech, T. (2008) Conservation short cut, or long and winding road? A critique of umbrella species criteria. Oryx, 42, 240-245.

Vos, C.C., Verboom, J., Opdam, P.F.M. \& Ter Braak, C.J.F. (2001) Toward ecologically scaled landscape indices. American Naturalist, 157, 24-41.

Watson, J., Freudenberger, D. \& Paull, D. (2001) An assessment of the focal species approach for conserving birds in variegated landscapes in southeastern Australia. Conservation Biology, 15, 1364-1373.

Westphal, M.I. \& Possingham, H.P. (2003) Applying a decision-theory framework to landscape planning for biodiversity: follow-up to Watson et al. Conservation Biology, 17, 327-330.

Whitmee, S. \& Orme, C.D.L. (2012) Predicting dispersal distance in mammals: a traitbased approach. Journal of Animal Ecology, in press DOI?

Youngentob, K., Lindenmayer, D.B. \& Wood, J. (2012) The response of arboreal marsupials to landscape context over time: a large-scale fragmentation study revisited. Biological Conservation, in press DOI? 


\section{Biosketch}

Emily Nicholson is a Centenary Research Fellow at the University of Melbourne. Her research focuses on decision-making for conservation and environmental management using a structured approach, where the goals, constraints and uncertainties are made explicit. Applications include risk assessment, scenario modelling, conservation planning, modelling social-ecological systems, and decision-making under uncertainty.

Author contributions: E.N. and H.P.P conceived the ideas; data were provided by D.B.L.; E.N. performed the analyses. All authors contributed to the writing of the manuscript, led E.N. 


\section{Tables \& figures}

Table 1. Model parameters for the ten study species: home range size $H_{k}$ (ha), fecundity (output of female dispersers) $\gamma_{k}$, mean dispersal distance $d_{k}$, and extinction-area exponent $x_{k}$; habitat quality $h_{i k}$ in each habitat type, where $h_{i k}=1$ denotes optimal habitat; and the references used to estimate parameters.

\begin{tabular}{|c|c|c|c|c|c|c|c|c|c|c|c|}
\hline \multirow[t]{2}{*}{ Species } & \multirow[t]{2}{*}{$H_{k}$} & \multirow[t]{2}{*}{$\gamma_{k}$} & \multirow[t]{2}{*}{$d_{k}$} & \multirow[t]{2}{*}{$x_{k}$} & \multicolumn{3}{|c|}{ Habitat type } & \multirow[b]{2}{*}{ E. viminalis } & \multirow[b]{2}{*}{ Stream } & \multirow[b]{2}{*}{ Slope } & \multirow[t]{2}{*}{ References } \\
\hline & & & & & E. camphora & E. macrorhynca & E. radiata & & & & \\
\hline $\begin{array}{l}\text { Greater glider, } \\
\text { Petaurus volans }\end{array}$ & 3 & 0.15 & 2.0 & 0.87 & 0.33 & 0.69 & 0.4 & 1 & & & $\begin{array}{l}\text { Possingham et al (1994), } \\
\text { McCarthy et al (2001) }\end{array}$ \\
\hline $\begin{array}{l}\text { Mountain brushtail possum } \\
\text { Trichosurus cunninghamii }\end{array}$ & 4 & 0.12 & 5 & 1.00 & 1 & 0 & 0.17 & 0.33 & & & $\begin{array}{l}\text { Lindenmayer et al (1999), } \\
\text { McCarthy et al (2001) }\end{array}$ \\
\hline $\begin{array}{l}\text { Common ringtail possum, } \\
\text { Pseudocheirus peregrinus }\end{array}$ & 2 & 0.40 & 0.85 & 0.78 & 1 & 0.25 & 0.5 & 1 & & & $\begin{array}{l}\text { Lindenmayer et al (2000), } \\
\text { McCarthy et al (2001) }\end{array}$ \\
\hline $\begin{array}{l}\text { Common brushtail possum, } \\
\text { Trichosurus vulpecula }\end{array}$ & 4 & 0.45 & 1 & 1.30 & 1 & 0.4 & 0.2 & 0.2 & & & $\begin{array}{l}\text { Lindenmayer et al (1999), } \\
\text { Johnson et al (2005) }\end{array}$ \\
\hline $\begin{array}{l}\text { Red-browed treecreeper, } \\
\text { Climateris erythrops }\end{array}$ & 10 & 0.55 & 1 & 1.20 & 1 & 0.25 & 0.5 & 1 & & & McCarthy et al. (2000) \\
\hline $\begin{array}{l}\text { White throated treecreeper, } \\
\text { Cormobates leucophaea }\end{array}$ & 5 & 0.41 & 5 & 1.40 & 0.5 & 1 & 1 & 1 & & & McCarthy et al. (2000) \\
\hline $\begin{array}{l}\text { Laughing kookaburra, } \\
\text { Dacelo novaeguineae }\end{array}$ & 5 & 0.35 & 20 & 1.60 & 0.7 & 0.85 & 1 & 0.55 & & & Lindenmayer et al.(2001) \\
\hline $\begin{array}{l}\text { Sacred Kingfisher, } \\
\text { Todiramphus sanctus }\end{array}$ & 7.5 & 0.70 & 15 & 1.15 & 0.7 & 1 & 1 & 1 & & & Lindenmayer et al.(2001) \\
\hline $\begin{array}{l}\text { Bush rat, } \\
\text { Rattus fuscipes }\end{array}$ & 0.2 & 1.25 & 0.1 & 0.72 & & & & & 1 & 0 & $\begin{array}{l}\text { Lindenmayer \& Lacy } \\
\text { (2002), Ball et al (2003), } \\
\text { Peakall \& Lindenmayer } \\
\text { (2006) }\end{array}$ \\
\hline $\begin{array}{l}\text { Agile antechinus, } \\
\text { Antechinus agilis }\end{array}$ & 1 & 1.20 & 5 & 0.45 & & & & & 1 & 0.5 & $\begin{array}{l}\text { Lindenmayer \& Lacy } \\
\text { (2002), Ball et al (2003) }\end{array}$ \\
\hline
\end{tabular}


Table 2. The models for estimating the probability of extinction of species $k$ in reserve system $\mathrm{r}, p_{k}(\mathbf{r}): M$ is the number of patches in the metapopulation, in this case the number of patches in the reserve system $\mathbf{r}$ which are suitable for the species, $d_{i j}$ is the centre-tocentre distance between patches $i$ and $j, d_{k}$ is the mean dispersal distance of species $k$, $\gamma_{k}$ is the estimated average number of female juveniles produced annually by a breeding female, $A_{i}$ is the size of patch $i$ in hectares, $H_{k}$ is the typical home range size for breeding females of species $k, h_{i k}$ is the proportional decrease in the density of species $k$ in patch $i$ given a sub-optimal habitat type (Table 1), and $x_{k}$, is the extinction-area exponent.

\begin{tabular}{ll}
\hline Model/sub-model & Formula \\
\hline Probability of extinction: & $p_{k}(\mathbf{r})=1-e^{-100 / T_{k}(\mathbf{r})}$ \\
\hline Mean time to extinction: & $T_{k}(\mathbf{r}) \approx T_{k}^{a}=\frac{1}{v_{a g g}} \frac{(M-1) !}{M(M-1)^{M-1}} e^{M / z} z^{M-1}$ \\
\hline $\begin{array}{l}\text { Aggregation of the effective } \\
\text { colonization abilities of the } \\
\text { subpopulations: }\end{array}$ & $z=\prod_{i=1}^{M} \max \left(\sqrt{2}, \sqrt{\left.\left\{\frac{1}{2}\left[\left(\frac{\sum_{j(\neq i)} c_{i j}}{v_{i}}\right)^{-2}+\left(\frac{\sum_{j(\neq i)} c_{j i}}{v_{i}}\right)^{-2}\right]\right)^{-1}\right)^{1 / M}}\right)^{\text {Effective local extinction rate: }}$ \\
& $v_{a g g}=\left(\prod_{i=1}^{M} v_{i}\right)^{1 / M}$ \\
\hline Local extinction rate in patch $i:$ & $v_{i}=\frac{-\ln (0.01)}{100}\left(\frac{A_{i} h_{i k}}{H_{k}}\right)^{-x_{k}}$ \\
\hline $\begin{array}{l}\text { Colonization rate from patch } i \\
\text { to patch } j:\end{array}$ & $c_{i j}=\gamma_{k} \frac{A_{i} h_{i k}}{H_{k}} b e^{-d_{i j} / d_{k}}$ \\
& and $b=0.5$ when $b=\frac{1}{\pi} \arctan \left(\frac{\sqrt{A_{j} / \pi}}{d_{i j}}\right)$ for $d_{i j} \geq \sqrt{A_{j} / \pi}$ \\
\hline
\end{tabular}


Table 3. The three focal species, with their overall ranking according to each criterion representing life-history traits, where 1 is the most limited species for the criterion: the species with largest home range, the red-browed treecreeper, is the most area-limited species, while the mountain brushtail possum is the least fecund, and the bush rat the most dispersal-limited.

\begin{tabular}{lccc}
\hline Species & Home range, $H_{k}$ & Fecundity, $\gamma_{k}$ & Mean dispersal distance, $d_{k}$ \\
\hline Red-browed treecreeper & $\mathbf{1}$ & 7 & 3 \\
Mountain brushtail possum & 5 & $\mathbf{1}$ & 6 \\
Bush Rat & 10 & 10 & $\mathbf{1}$ \\
\hline
\end{tabular}


Table 4. Extinction risks of each species in the best single-species reserve systems, the rank order by extinction risk in single-species solutions (starting at the most extinctionprone); the extinction risks of each species in the best ten-species reserve system, with their rank order by extinction risk under the ten-species solution; and the number of three-species solutions that matched the single species solution of each species - the most extinction-prone species had more three-species solutions that matched their singlespecies optimum.

\begin{tabular}{lccccc}
\hline Species & $\begin{array}{l}\text { Single-species } \\
\text { solutions }\end{array}$ & $\begin{array}{l}\text { Rankby } \\
\text { extinction risk } \\
\text { in single-species }\end{array}$ & $\begin{array}{l}\text { Ten-species } \\
\text { solution }\end{array}$ & $\begin{array}{l}\text { Rank by } \\
\text { extinction risk } \\
\text { in ten-species }\end{array}$ & $\begin{array}{l}\text { Three-species } \\
\text { solutions same } \\
\text { as single- } \\
\text { species }\end{array}$ \\
\hline Red-browed treecreeper & 0.0038 & 1 & 0.0049 & 2 & 21 \\
Mountain brushtail & 0.0001 & 2 & & & \\
possum & $4.7110^{-5}$ & 3 & 0.0013 & 3 & 15 \\
Bush rat & $1.2810^{-5}$ & 4 & 0.0009 & 4 & 0 \\
Greater glider & $<1.0010^{-5}$ & 5 & $<1.0010^{-5}$ & 5 & 10 \\
Common ringtail possum & $<<1.0010^{-5}$ & 6 & $<1.0010^{-5}$ & 7 & 10 \\
Common brushtail possum & $<<1.0010^{-5}$ & 7 & $<1.0010^{-5}$ & 6 & 0 \\
Sacred Kingfisher & $<<1.0010^{-5}$ & 8 & $<<1.0010^{-5}$ & 9 & 0 \\
Laughing kookaburra & $<<1.0010^{-5}$ & 9 & $<1.0010^{-5}$ & 8 & 0 \\
White throated treecreeper & $<<1.0010^{-5}$ & 10 & $<<1.0010^{-5}$ & 10 & 0 \\
Agile antechinus & - & 0.0133 & & 0 \\
\hline $\begin{array}{l}\text { Expected number of } \\
\text { extinctions }\end{array}$ & - & & & & 0 \\
\hline
\end{tabular}


Figures

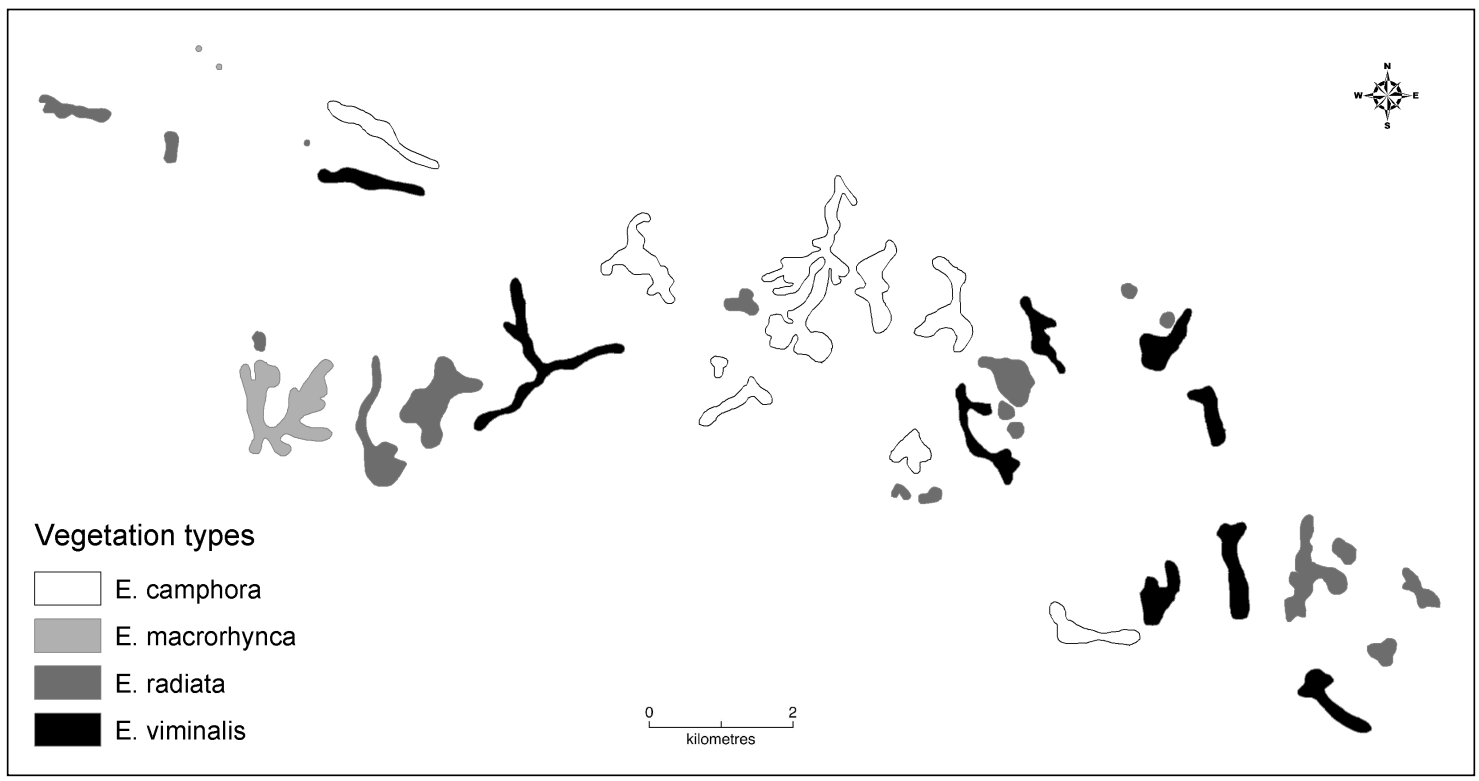

Figure 1. The 39-patch study system, showing the four vegetation types that provide the basis for the habitat quality estimates for each species (Table 1). 


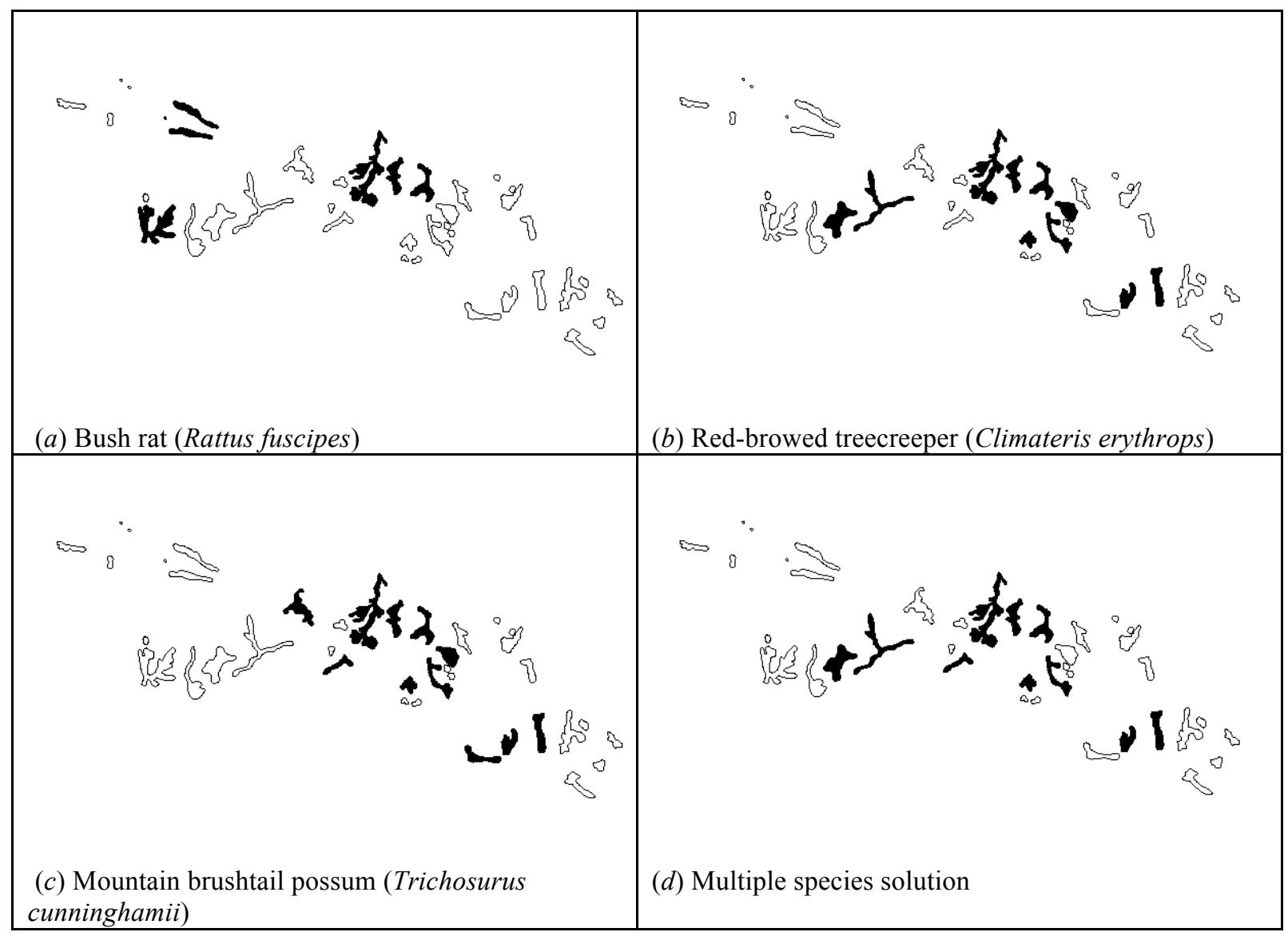

Figure 2. The reserve systems (black) that minimize the expected number of extinctions for each of the focal species (a-c), and across all ten species and also the three focal species (d). 